\title{
Dijital Ekonomi ve Göstergelerinin Sürdürülebilir Kalkınma Üzerindeki Etkisi: AB Ülkeleri Örneği
}

\author{
The Impact of Digital Economy and Its Indicators on Sustainable Development: The Case of EU \\ Countries
}

\section{Betül ALTAY TOPCU}

Doç. Dr., Kayseri Üniversitesi, Teknik Bilimler MYO,

Pazarlama ve DlşTicaret Bölümü, batopcu@kayseri.edu.tr

https://orcid.org/0000-0003-2044-4568
Makale Başvuru Tarihi: 28.06.2021

Makale Kabul Tarihi: 28.08 .2021

Makale Türü: Araştırma Makalesi

\section{Anahtar \\ Kelimeler: \\ Dijtal Ekonomi, \\ Sürdürülebilir \\ Kalkınma,}

$A B$,

Keywords:

Digital Economy,

Sustainable

Development,

$E U$,

\section{ÖZET}

Bu çalıșmada 28 AB ülkesinde Uluslararası Dijital Ekonomi ve Toplum İndeksi ve bu indekse ait alt göstergelerin sürdürülebilir kalkınma indeksi üzerindeki etkisinin 2018 yll için yatay kesit veri analiz yöntemi kullanılarak araştırılması amaçlanmışıtır. Çalışma bu etkinin AB ülkelerinde hangi dijital ekonomi göstergesi veya göstergelerinden kaynaklandiğının belirlenmesi açısından önemlidir. Analiz sonuçlarına göre $A B$ ülkelerinde dijital ekonominin sürdürülebilir kalkınma üzerindeki etkisi pozitif ve istatistiksel olarak anlamlıdır. Başka bir ifadeyle söz konusu ülkelerde dijital ekonomideki artış sürdürülebilir kalkınmayı artırmaktadır. AB tarafindan ölçülen beş dijital ekonomi göstergelerinden olan ve işletmelerin dijitalleşmesi ve çevrimiçi satış kanallarının geliştirilmesini ifade eden dijital teknolojiye entegrasyon indeksinin, sürdürülebilir kalkınma indeksi üzerindeki etkisi pozitif ve istatistiksel olarak anlamlıdır. Bu indeksin dışında kalan diğer dijital ekonomi göstergelerinin sürdürülebilir kalkınma üzerinde etkisinin olmadı̆̆ sonucuna ulaşılmıştır. Analiz bulguları AB ülkelerinin sürdürülebilir kalkınma düzeyinin artmasında dijital ekonomi göstergelerinden sadece dijital teknolojiye entegrasyon indeksinin etkili olduğunu göstermiştir. 


\section{GIRISS}

Küreselleşme olgusu dünya ekonomisinin hızlı bir şekilde dönüşüm geçirmesine neden olmaktadır. Bu dönüşüm bilgi ve iletişim teknolojileri (BIT) temeline dayalı olarak ekonomik işlemlerin ve mevcut iş yapma şekillerinin değişimi olarak ifade edilen dijital ekonomi kavramını ortaya çıkarmaktadır (Mastar Özcan, 2016:73). Ülkelerin sürdürülebilir kalkınma hedeflerine ulaşmasında en önemli faktörlerden biri de dijital ekonomideki gelişmelerdir. Günümüzde BİT'de yaşanan gelişmeler ile birlikte dijitalleşme eğilimlerinin giderek artması birçok faaliyetin dijital ortamlarda gerçekleşmesine sebep olmuştur. (Yeşilorman ve Koç, 2014:127). Tüketiciler dijital ortamda birçok alternatif içerisinden istedikleri özellikteki ürünü hızlı bir şekilde karşılaştırma, seçme ve satın alma imkânına sahiptir. $\mathrm{Bu}$ durum yurtiçi ve yurtdışında faaliyet gösteren işletmeleri rekabete zorlamaktadır. $\mathrm{Bu}$ nedenle dijitalleşmenin ekonomi üzerindeki etkileri büyük önem taşımaktadır (Taşel, 2020:127). Özellikle günümüzde yaşanan küresel Covid-19 salgını da işletmelerin müşterilerine ulaşabilmek için dijital teknolojilerden yaralanmasını zorunlu hale getirmektedir (Serinikli, 2021:279).

Dünya genelinde dijital ekonominin kullanımı giderek yaygınlaşmaktadır. AB'nin de içinde bulunduğu birçok kurum ve kuruluş sınır ötesi dijital ekonomiyle ilgili faaliyetlere yönelik engellerin kaldırılması amacıyla çeşitli stratejiler benimsemektedir. AB'de bu amaca yönelik çalışmalar, 2000 yılında yapılan ve Lizbon Stratejisi olarak bilinen Avrupa zirvesi ile başlamış ve 2020 stratejisi ile sürmüştür. Bu stratejilerde, BíT'lerin ekonomik büyüme, istihdam ve inovasyon gibi alanlarda sağlayacağı imkânlardan AB'nin yararlanabilmesi için yapılması gerekenler belirtilmiştir. Ayrıca AB'nin bilgi toplumuna dönüştürülmesi ile bölgede "Dijital Tek Pazar" oluşturulmasının önemli olduğu üzerinde durulmuştur (Konu, 2020:664).

Bu çalışmada ilk olarak 28 AB ülkesinde 2018 yılı için Avrupa Komisyonu tarafından hazırlanan uluslararası dijital ekonomi ve toplum indeksinin, sürdürülebilir kalkınma indeksi üzerindeki etkisinin yatay kesit veri analizi kullanılarak araştırılması amaçlanmıştır. Daha sonra söz konusu indekse ait beş alt göstergenin, sürdürülebilir kalkınma üzerindeki etkisi incelenmiştir. Literatürde dijital ekonomi ve ekonomik büyüme arasındaki ilişkiyi araştıran çalışmalar olmasına rağmen, dijital ekonominin sürdürülebilir kalkınma üzerindeki etkisini araştıran çalışmalar sınırlıdır. Bu çalışma, dijital ekonomi göstergelerinin de analize dâhil edilmesi ve bu göstergelerin sürdürülebilir kalkınma üzerindeki etkinliğinin belirlenmesi ile literatüre katkı sağlayabilmeyi amaçlaması açısından önemlidir. Çalışma dört bölümden oluşmaktadır. Çalışmada giriş bölümünü takiben ikinci bölümde dijital ekonomi ve sürdürülebilir kalkınma kavramlarına yer verilmiştir. Üçüncü bölümde konuya ilişkin literatür özetlenmiştir. Dördüncü bölümde model, veri ve analiz sonuçlarına ait değerlendirmeler yapılmıştır. Çalışma sonuç bölümü ile tamamlanmıştır.

\section{DİJITTAL EKONOMİ VE SÜRDÜRÜLEBİLİR KALKINMA}

\subsection{Dijital Ekonomi ve Kapsamı}

Dijitalleşme, sanayi devrimi ile birlikte global ekonomideki en önemli gelişmelerden biri haline gelmiştir. Globalleşme özellikle de ticari işlemlerin dijitalleşmesine neden olarak, dijital ekonomi kavramını gündeme getirmiştir. Teknolojide yaşanan gelişmeler ulusal ve uluslararası ölçekte üretim yapan işletmelerin faaliyetlerinde dinamik değişimlere sebep olmaktadır (Akkaya ve Gerçek, 2019:167).

Dünyada BİT’lerde ortaya çıkan hızlı gelişmeler, internetin yaşamın birçok alanında yoğun olarak kullanılmasına neden olmuştur. Bu çerçevede dijital ortamda gerçekleştirilen ticari işlemler ortaya çıkmış ve bu işlemler giderek artış göstermiştir. Bu teknolojilerin yaygın olarak kullanılması, ekonomi literatüründe "İnternet Çăğ", "Bilgi Teknolojisi Devrimi" ve "Dijital Ekonomi" gibi kavramların ortaya çıkmasına neden olmuştur. Dünya genelinde dijital ekonomi kavramı yerine; tekonomi, bilgi ekonomisi, enformasyon ekonomisi, ă ekonomisi ve yeni ekonomi gibi kavramlar da kullanılmaktadır (Barışık ve Yirmibeşcik, 2006:40). Özellikle eticaretin gelişmesiyle, ürün ve hizmetlerin internet ortamında farklı ödeme seçenekleriyle satın alınması dijital ekonomi olarak adlandırılan yeni bir ekonomik düzeni ortaya çıkarmıştır (Altay Topcu ve Sümerli Sarıgül, 2020:28).

Ekonomi literatürüne djjital ekonomi kavramı ilk kez Tapscott tarafindan 1995'de yayımlanan "The Digital Economy: Promise and Peril in the Age of Networked Intelligence" adlı kitabı ile kazandırılmıştır. Tapscott (1995), yeni ya da dijital ekonomi kavramını şu şekilde tanımlamaktadır; "Bilgisayarlarda depolanan ve ağlar arasında ışılk hızında yarışan bilgi tüm yönleriyle dijital hale gelmektedir. Bu şekilde oluşturulan yeni olanaklar dünyası, fiziksel temelli tüm etkileşimlerin gerçekleştiği eski paradigma olan dilin icadı kadar önemlidir". 
Carlsson (2004) dijital ekonomiyi, "BİT’ler tarafindan sağlanan ekonomik faaliyetlerin ve mesleki etkileşimlerin küresel ölçekte oluşturduğu ağ ya da djital teknolojilere dayanan ekonomi", olarak ifade etmektedir. Dinana (2019)'a göre dijital ekonomi, "BİT’ler tarafindan sağlanan küresel bir ekonomik ve sosyal faaliyetler ă̆ı", olarak adlandırmaktadır.

Drucker (1993)'e göre yeni ekonomide bilgi bugün tek anlamlı kaynaktır. Toprak, emek ve sermaye gibi geleneksel üretim faktörleri ortadan kaybolmamakla birlikte ikinci plana itilmiştir. Bilginin olduğu her yerde bu kaynaklara rahatlıkla ulaşılabilir. Bu yeni anlamda ortaya çıkan bilgi, ekonomik ve sosyal amaçlara ulaşabilmek için bir fayda anlamında bilgidir. OECD (2019) dijital ekonomiyi, "teknolojiyi daha ucuz ve daha güçlü hale getiren, iş süreçlerini standartlaştıran ve ayn zamanda ekonomideki bütün sektörlerde yeniliği teşvik eden değişim süreçleri”, şeklinde tanımlamıştır. Bukht ve Heeks (2017)'ye göre dijital ekonomi, "yalnızca veya esas olarak dijital mal veya hizmetlere dayalı bir iş modeliyle dijital teknolojilerden elde edilen ekonomik çıktının bir parçası", olarak ifade edilmektedir. Dijital ekonominin kapsamı Şekil 1'de gösterilmektedir.

Şekil 1. Dijital Ekonominin Kapsamı

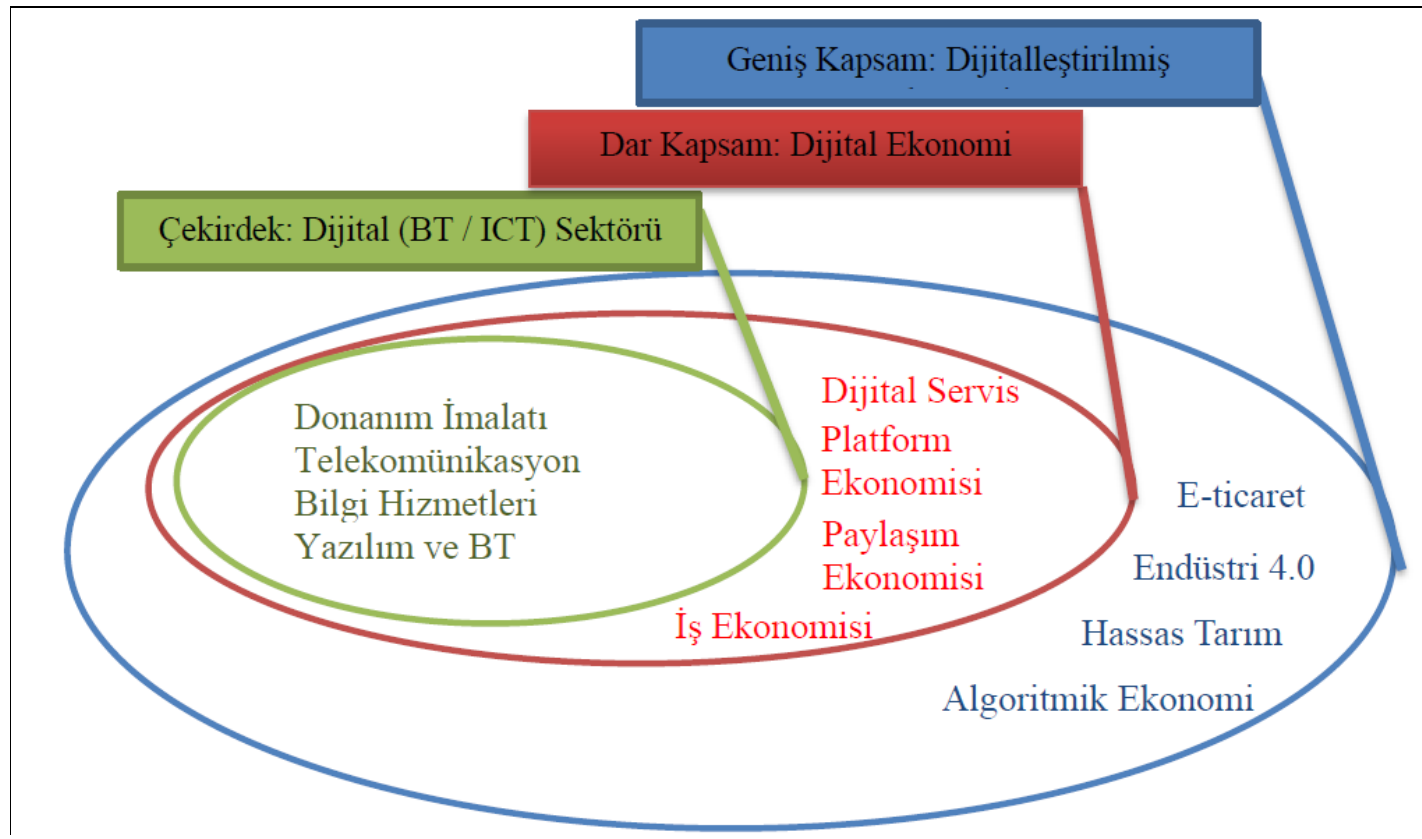

Kaynak: Bukht ve Heeks, 2017:13; Dikkaya ve Aytekin, 2019:1286.

Şekil 1'de dijital ekonominin çekirdek kısmını donanım, telekomünikasyon, bilgi hizmetleri ve yazılım sektörleri oluştururken; dijital ekonominin dar kapsamını dijital servis, platform, paylaşım ve iş ekonomisi oluşturmaktadır. Günümüzde yoğun olarak kullanılan en kapsamlı kısmını ise e-ticaret, endüstri 4.0, hassas tarım ve algoritmik ekonomi oluşturmaktadır.

Dijitalleşme ve internet, yeni yazılımlarla birlikte firmaların tedarikçiler ve müşteriler ile yeni yöntemlerle işbirliği yapmalarına ve böylece üretkenliklerini artırmalarına katkı sağlar. Dijitaleşme ile birlikte bilgiye erişmek ve müşterilerin ihtiyaçlarına hızlı bir şekilde yanıt vermek mümkündür. Web teknolojisinin kullanımı ve doğru yönetimi ile distribütörler ürün tasarlama ve geliştirme süreçlerinde eskisinden daha kolay yer almaktadır. Ayrıca, doğrudan tedarikçi bağlantısına sahip bir distribütör, satıcılar ile müşterilerin siparişlerinin beklemeden alınmasına neden olmaktadır. Bu işlem, sipariş döngüsünü günlerden dakikalara indirebilmektedir. Böylece yazılım teknolojisi, daha sonra kullanılabilecek işlemler hakkında bilgi depolamayı mümkün kilmaktadır (Carlsson, 2004:256).

\subsection{Sürdürülebilir Kalkınma, Boyutları ve Hedefleri}

Ekonomik büyüme mal ve hizmet üretimde bir artışı ifade ederken, kalkınma insanı da içine alan daha geniş kapsamlı bir kavramı tanımlamaktadır. Sürdürülebilir kalkınma, kalkınmanın sürdürülebilir olması, başka bir ifadeyle süreklilik taşıması anlamında kullanılmaktadır. Bu kavram, insan ile doğa arasında denge kurarak doğal kaynakları tüketmeden, gelecek nesillerin kendi ihtiyaçlarını karşılayabilmelerine imkân veren, bugünün ihtiyaçlarını karşılayan bir gelişme olarak ifade edilmektedir (Kaypak, 2011:22). Başka bir ifadeyle insan sağlığının ve doğanın korunması ile ekonomik kalkınmanın sürekliliğini sağlayacak şekilde doğal kaynakların 
akılcı bir şekilde yönetimi ve gelecek nesillere yakışır bir doğal, fiziksel ve sosyal çevre bırakılmasıdır. Bu yaklaşım kalkınmanın her aşamasında ekonomik ve sosyal politikaların, çevre politikaları ile bir arada değerlendirilmesini gerekli kılmaktadır (Tıraş, 2012:60). Sürdürülebilir kalkınma stratejisinde, temel prensip ekonomik, sosyal ve ekolojik düşünceleri bütünleştirmektir (Bilgili, 2017:560). Bu çerçevede sürdürülebilir kalkınmanın ekonomik, sosyal ve çevre boyutlarından söz edilebilir (Anuşlu ve Fırat, 2020:47; Palich ve Edmonds, 2013:1; Trraş, 2012:61; Vivien, 2008:4-5; Bilgili, 2017:563-565; Morelli, 2011:6);

- Ekonomik Boyut: Genel olarak sürdürülebilir kalkınmanın ekonomik boyutu sermayenin korunmasını ifade etmektedir. Sürekli olarak mal ve hizmetleri üretebilen, tarımsal ve imalat sanayi üretimini destekleyerek sektörel dengesizlikleri gideren, iç ve dış borçların sürdürülebilirliğini sağlayan sistem olarak da tanımlanabilir. Sürdürülebilirliğin bu boyutunda kaynakların tükenme potansiyeli önem arz etmektedir. Dolayısıyla sürdürülebilirliğin ekonomik boyutu; atık maddelerin yeniden hammaddeye dönüştürülmesi, mal ve hizmet üretiminde daha az girdi kullanılması, üretim süreçleri sonucunda ortaya çıkan atıkların geri dönüştürülmesi gibi süreçleri kapsamaktadır.

- Sosyal Boyut: Sürdürülebilir kalkınmanın sosyal boyutu; eğitim ve sağlık gibi hizmetlerin yeterli olması ve toplumda eşit dağılımı, cinsiyet eşitliği, politik sorumluluk ve katılımın sağlanması olarak tanımlanabilir. Sürdürülebilir kalkınmanın bu boyutu toplumda yaşayan bireylerin temel ihtiyaçlarının karşılanmasını ifade etmektedir. Sosyal açıdan toplumların sürdürülebilirliği; kendi kaynaklarını koruma altına alan, geliştiren ve gelecekte ortaya çıkabilecek sorunlarını çözebilen bir topluma vurgu yapmaktadır. Bir başka ifadeyle, sosyal boyutuyla sürdürülebilirlik, topluma karşı duyarlılığı ve toplumsal refahı destekleyen fiziksel, kültürel ve sosyal ortamların oluşturulması, bu ortamlarda yaşayan insanlarla iletişim kurabilme sürecini ifade etmektedir.

- Çevre Boyutu: Sürdürülebilir kalkınmanın çevre boyutu yenilenebilir enerji kaynaklarının çevreye verdiği zararın minimum düzeye indirilmesi, biyolojik çeşitliliğin sağlanması, atmosferik denge ve diğer ekosistem unsurlarının korunmasını da içeren bir sistem olarak tanımlanabilir. Başka bir ifadeyle çevresel sürdürülebilirlik, mevcut ve gelecek nesillerin kaynak ve hizmet ihtiyaçlarını karşılayabilme yeteneğidir. $\mathrm{Bu}$ çerçevede insanların ihtiyaçlarını karşılayan ekosistemlerin dayanıklılık, esneklik ve bağlantılı olma ilkelerini göz önünde bulundurarak, ekosistemlerin kendilerini yeniden oluşturabilme özelliklerine dikkat eden ve biyolojik çeşitliliği artıran faaliyetlerdir.

Birleşmiş Milletler tarafından önerilen sürdürülebilir kalkınma hedefleri Şekil 2'de gösterilmektedir.

Şekil 2. Sürdürülebilir Kalkınma Hedefleri
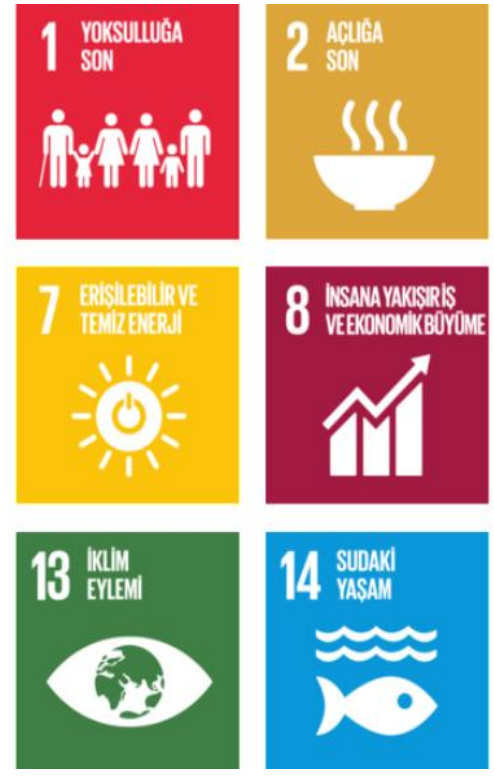
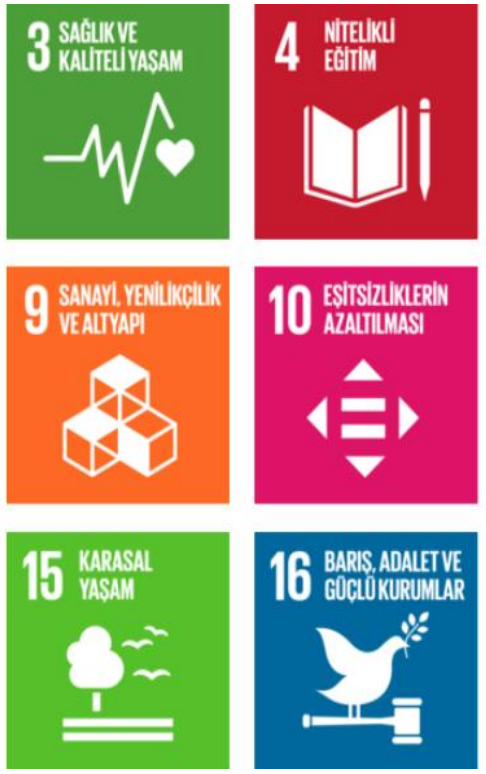
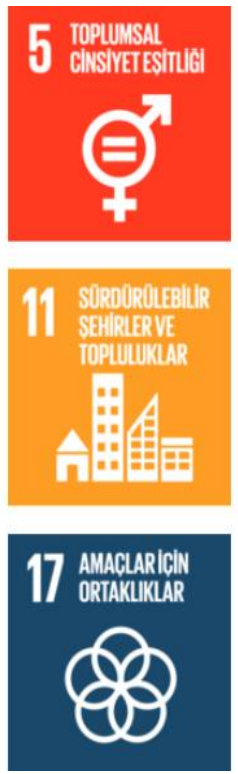
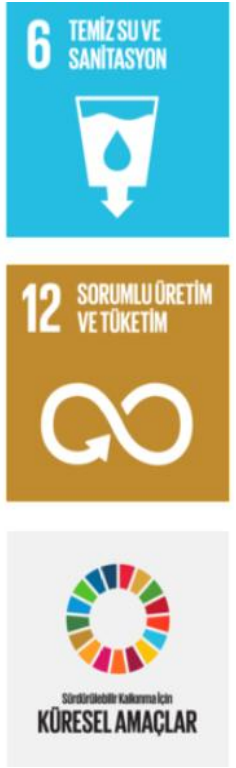

Kaynak: United Nations, The Sustainable Development Goals, https://sdgs.un.org/goals (E. T.: 20.05.2021).

Şekil 2'de görüldüğü gibi Birleşmiş Milletler tarafından önerilen 17 sürdürülebilir kalkınma hedefi vardır. Bu hedeflere ulaşabilmek için BİT'lerdeki gelişmeler önemli bir araç olarak görülmektedir. Böylece oluşturulabilecek dijital çözümler dünya ekonomilerinin hızlı bir şekilde dönüşümüne neden olacaktır. 


\section{ARAȘTIRMANIN UYGULANMASI VE ANALIZİ}

\subsection{Literatür Taraması}

Literatürde dijital ekonominin ekonomik büyüme üzerindeki etkisini inceleyen çalışmalar olmasına rağmen, dijital ekonominin sürdürülebilir kalkınma üzerindeki etkisini inceleyen çalışmalar sınırlı sayıdadır ve dijitalleşmenin yaygınlaşması ile birlikte son dönemlerde yoğunluk kazanmıştır. Çalışmanın bu bölümünde dijital ekonominin ekonomik büyüme ve ağırlıklı olarak sürdürülebilir kalkınma üzerindeki etkisini inceleyen çalışmalara yer verilmiştir.

Tocan ve Duduman (2010) BİT'lerin gelişimi ile yaygınlaşan dijital ekonominin bilgilerin hızlı bir şekilde iletilmesini sağlayarak sürdürülebilir kalkınmayı tetiklediğini, aynı zamanda sürdürülebilir kalkınmanın da dijital ekonominin gelişimine katkı sağladığını ileri sürmüşlerdir. Hilty ve Hercheui (2010), BİT’lerin sürdürülebilir kalkınma üzerindeki etkisini incelemişlerdir. Ekonomide karar vericilerin BíT'leri etkin olarak kullandığında, sürdürülebilir kalkınmanın gelişeceğini belirtmişlerdir.

Jovanović vd. (2018), modern iş hayatındaki en büyük dönüşümün, ülkelerin rekabet güçlerinin artmasına katkı sağlayan geleneksel iş modellerinden dijital iş modellerine geçmek olduğunu ileri sürmüştür. Sürdürülebilir kalkınmada ülkelerin refaha ulaşması kalkınmanın tüm boyutlarının birlikte ele alınması ile mümkündür. Özellikle sürdürülebilir kalkınmanın kültür boyutu, dijital dönüşümün toplum tarafindan benimsenmesi açısından önemli bir faktördür. Kültür ve kültürel değişimin farklı boyutları, toplumu değiştirmek ve toplumun sürdürülebilir kalkınmasını etkilemek için gereklidir.

Hegyes vd. (2017), AB tarafından yayınlanan raporlara dayalı olarak Macaristan ve AB arasındaki dijital beceri ve yeterliliklerin karşılaştırmalı analizini yapmışlardır. Çalışmanın ana bulguları, Macaristan'ın Avrupa ortalamasına kıyasla dijital beceriler açısından daha iyi bir konuma sahip olduğunu göstermiştir. Bilgi toplumunun sürdürülebilir kalkınmada önemli bir rol üstlendiğini ileri sürmüşlerdir.

Deniz (2018), dijital ekonomideki gelişmelerin dünya genelinde ekonomik büyüme ve verimliliği artırdığını ifade etmiştir. Dijitalleşme küresel dünyada kalkınmanın bir ölçütü olarak görülmüş ve ülkeler için ulaşılması gereken bir hedef haline gelmiştir. Avrupa Komisyonu'nun 2017 yılında yayınladığı ve ülkelerin dijital ekonomi performanslarını gösteren DESI sonuçlarına göre, AB bir bütün olarak ilerleme kaydetmektedir. Ancak zirvedeki dijital oyuncular ile düşük performans sergileyen ülkeler arasındaki fark oldukça büyüktür. AB'de "Dijital Tek Pazar"ın oluşturulması için daha fazla yatırıma ihtiyaç vardır. Bu indeks sonuçlarına göre Türkiye inovasyonda gelişme göstermekle birlikte, araştırma alanında takip edilmesi gereken ülkeler arasında yer almaktadir.

David (2019), bazı Afrika ülkelerinde 2000-2015 döneminde panel veri analizi ile telekomünikasyon altyapısı, ekonomik büyüme ve kalkınma arasındaki nedensellik ilişkisini analiz etmiştir. Analiz bulgularına göre değişkenler arasında uzun vadeli bir nedensellik ilişkisinin olduğu tespit edilmiştir. Rezny vd. (2019), bilgi ekonomisinin genellikle hem daha yüksek hem de sürdürülebilir ekonomik büyüme elde etmek için radikal bir toplumsal dönüşümün yolu olduğunu ve artan kaynak kıtlı̆̆ı ve iklim bozulması çıkmazından bir çııış yolu olduğunu ifade etmişlerdir.

Pradhan vd. (2019), 25 AB ülkesi için 1989-2016 döneminde BİT altyapıs1, ekonomik büyüme ve risk sermayesi arasındaki ilişkiyi panel veri analizi ile incelemişlerdir. Analiz bulguları uzun dönemde BİT altyapısındaki gelişmeler ve ekonomik büyümenin risk sermayesi yatırımlarının tüm aşamalarını etkilediğini göstermiştir. Çalışmada ayrıca ekonomik büyümenin ve geç dönem risk sermayesi yatırımının internet kullanımını etkilediğini ve internet kullanımı ve geç dönem risk sermayesinin ekonomik büyümeyi etkilediğini göstermiştir.

Dinana (2019), BİT'in Birleşmiş Milletler tarafından önerilen 17 sürdürülebilir kalkınma hedefleri üzerindeki etkisini değerlendirmiştir. Dijitalleşmenin, ekonomiyi etkileyen en önemli faktörlerden biri olduğunu ifade etmiştir. Yoksulluğun ortadan kaldırılmasından, iklim değişikliği, küresel ortaklığın sayısına kadar her hedefin, dijitalleşmenin benimsenmesiyle olumlu yönde etkilendiğini ileri sürmüştür.

Konu (2020), AB ülkelerinde dijital ekonomi ve sürdürülebilir kalkınma arasındaki ilişkiyi yatay kesit veri analizi yöntemi ile 2018 DESI'dan yararlanarak araştırmıştır. Araştırma sonucunda söz konusu ülkelerde dijital ekonominin sürdürülebilir kalkınmayı pozitif ve istatiksel olarak anlamlı düzeyde etkilediğini tespit etmiştir. AB'de dijitalleşmenin sürdürülebilir kalkınmanın temel itici güçlerinden biri olduğu sonucuna ulaşmıştır. 
Gözüküçük (2020), dijital ekonominin ekonomik büyüme üzerindeki etkisini 2005-2017 döneminde OECD ülkeleri için panel veri analizi ile araştırmıştır. Analizde dijital ekonomiyi temsilen geniş bant aboneliği ve bireysel internet kullanımındaki artışların ekonomik büyümeyi artırdığı sonucuna ulaşılırken, sabit telefon aboneliğindeki artışın ekonomik büyümeyi azalttığı, mobil telefon aboneliğinin ise ekonomik büyüme üzerinde etkisinin olmadığı sonucuna ulaşılmıştır.

Li vd. (2020), DESI indeksinin Asya ülkelerinde topluma ve ekonomiye katkılarını analiz etmişlerdir. Asya ülkelerinin dijital ekonomisindeki gelişmelerin yüksek teknoloji, iş ve sosyal dönüşümler ve bilgiye dayalı değişmeler yoluyla bölgenin büyümesine katkıda bulunduğunu belirtmişlerdir. Bu ülkelerdeki dijital ekonomi süreci; teknoloji inovasyonu, büyüme odaklı hükümet politikaları ve dijital girişimcilik aracılığıyla iş süreçlerinin yenilenmesine katkıda bulunmuştur.

\subsection{Veri Seti, Model Ve Analiz Sonuçları}

Çalışmada 2018 yılı için dijital ekonomi ve göstergelerinin sürdürülebilir kalkınma üzerindeki etkisi, AB'ye üye 28 ülkede "En küçük kareler (EKK)" yöntemi kullanılarak yatay kesit veri analizi ile araştırılmıştır. Çalışmada bu etki iki ayrı model kullanılarak test edilmiş̧ir. 2018 yılının esas alınmasının nedeni, AB'nin yayınlamış olduğu 2020 raporunda dijital ekonomi ve göstergelerine ait en son verinin 2018 yılına ait olmasıdır. Çalışmada kullanılan bağımlı ve bağımsız değişkenler, bu değişkenlerin sembolleri ve veri kaynakları Tablo 1'de gösterilmektedir.

Tablo 1. Değiş̧kenler ve Veri Kaynakları

\begin{tabular}{|c|c|c|}
\hline \multicolumn{2}{|r|}{ Değişkenler ve Sembolleri } & Veri Kaynakları \\
\hline $\begin{array}{c}\text { Bağımlı } \\
\text { Değişken }\end{array}$ & Sürdürülebilir Kalkınma Hedefleri Endeksi-SDGI & $\begin{array}{c}\text { Bertelsmann Stiftung and Sustainable } \\
\text { Development Solutions Network-SDG Index and } \\
\text { Dashboards Report } 2018\end{array}$ \\
\hline $\begin{array}{l}\text { Bağımsız } \\
\text { Değişken }\end{array}$ & Uluslararası Dijital Ekonomi ve Toplum İndeksi-IDESI & $\begin{array}{l}\text { European Commission-International Digital } \\
\text { Economy and Society Index Report } 2020\end{array}$ \\
\hline \multirow{5}{*}{$\begin{array}{c}\text { Bağımsız } \\
\text { Değişken } \\
\text { IDESI } \\
\text { Göstergeleri }\end{array}$} & Bağlantı-C & \multirow{5}{*}{$\begin{array}{l}\text { European Commission-International Digital } \\
\text { Economy and Society Index Report } 2020\end{array}$} \\
\hline & İnsan Sermayesi-HC & \\
\hline & Vatandaşların İnternet Kullanımı-CUI & \\
\hline & Dijital Teknolojinin Entegrasyonu-IDT & \\
\hline & Dijital Kamu Hizmetleri-DPS & \\
\hline $\begin{array}{l}\text { Bağımsız } \\
\text { Değișken }\end{array}$ & Küresel Rekabet Gücü Endeksi-GCI & $\begin{array}{l}\text { World Economic Forum-The Global } \\
\text { Competitiveness Report } 2019\end{array}$ \\
\hline
\end{tabular}

Çalışmada kullanılan tüm değişkenlerin doğal logaritması alınmıştır. Tahmin edilen 1 ve 2 numaralı modeller aşağıda gösterildiği gibidir;

$$
\begin{aligned}
& L_{S D G I}=\alpha+b_{1} L_{i D E S I}+b_{2} L_{i t} L_{C I}+\varepsilon_{i t} \\
& L_{S D G I}=\alpha+b_{1} L C_{i t}+b_{2} L H C_{i t}+b_{3} L C U I_{i t}+b_{4} L I D T_{i t}+b_{5} L D P S_{i t}+\varepsilon_{i t}
\end{aligned}
$$

Model 1 ve 2'de görüldüğü gibi, analizde bağımlı değişken olarak kullanılan SDGI, Sürdürülebilir Kalkınma Hedefleri Endeksi'ni göstermektedir. Model 1'de bağımsız değişkenleri temsilen IDESI, Uluslararası Dijital Ekonomi ve Toplum İndeksi'ni; GCI, Küresel Rekabet Gücü Endeksi'ni ifade etmektedir. Model 2'de analize bağımsız değişken olarak dijital ekonomi göstergeleri dâhil edilmiştir. Modelde C, HC, CUI, IDT ve DPS sırasıyla Bağlantı, İnsan Sermayesi, Vatandaşların İnternet Kullanımı, Dijital Teknolojinin Entegrasyonu ve Dijital Kamu Hizmetleri değişkenlerini göstermektedir.

Çalışmada kullanılan Sürdürülebilir Kalkınma Hedefleri Endeksi (Sustainable Development Goals IndexSDGI), ülkelerin sürdürülebilir kalkınma hedeflerine ne ölçüde ulaştığını ölçen ve değerlendiren dünya ölçeğinde bir çalışmadır. Bu endeks 0-100 arasında değerler almaktadır. 0 sürdürülebilir kalkınma hedefinin en düşük olduğu değeri, 100 ise en yüksek olduğu değeri göstermektedir.

Dijital Ekonomi ve Toplum Endeksi raporu AB tarafından belirli yıllarda yayınlanmaktadır. AB'nin DESI olarak isimlendirdiği indeks ile hem toplumsal, hem de üretimdeki dijital gelişmeler ölçülmektedir. En son rapor ise 2020 yılında yayınlanan "Uluslararası Dijital Ekonomi ve Toplum Endeksi-IDESI" raporudur. Bu rapor, 
AB'ye üye olan ülkelerin dijital ekonomi performanslarını ve $\mathrm{AB}$ dışında kalan dünyadaki diğer 18 ülkenin (Avustralya, Brezilya, Kanada, Şili, Çin, İzlanda, İsrail, Japonya, Meksika, Yeni Zelanda, Norveç, Rusya, Sirbistan, Güney Kore, İsviçre, Türkiye, Birleşik Krallık ve Amerika Birleşik Devletleri) dijital ekonomi performanslarını karşılaştırmaktadır. Raporda söz konusu ülkelerin dijital ekonomi performanslarına ait genel skor bulunmaktadır. Ayrıca ülkelerin dijital ekonomi performanslarına ait alt göstergeler yer almaktadır. Bu endeks, 0-100 arasında değerler almaktadır. Bu çerçevede 0 değeri dijitalleşme düzeyinin en düşük olduğu seviyeyi, 100 değeri ise en yüksek olduğu seviyeyi göstermektedir (European Comission, 2020:6). IDESI'ya ait 5 gösterge bulunmaktadır. Bu göstergeler ve bu göstergelerin açıklamaları Tablo 2'de gösterilmektedir.

Tablo 2. IDESI Göstergeleri

\begin{tabular}{|c|c|}
\hline Göstergeler & Açıklamalar \\
\hline Bağlantı & Geniş bant altyapısının yaygınlaştırılması ve kalitesi \\
\hline İnsan Sermayesi & Dijital bir toplumun sunduğu olanaklardan yararlanmak için gereken beceriler. \\
\hline Vatandaşların İnternet Kullanımı & Vatandaşlar tarafından çevrimiçi olarak gerçekleştirilen faaliyetlerin çeşitliliği. \\
\hline Dijital Teknolojinin Entegrasyonu & İşletmelerin dijitalleşmesi ve çevrimiçi satış kanalının geliştirilmesi. \\
\hline Dijital Kamu Hizmetleri & Kamu hizmetlerinin dijitalleştirilmesi, e-devlete odaklanılması. \\
\hline
\end{tabular}

Kaynak: European Comission, 2020:7.

Tablo 2'de yer alan birinci gösterge olan bağlant1, sabit ve mobil ağlarda geniş bant ağ dağıtımlarını içermektedir. Endeksin insan sermayesi boyutu, internet kullanıcı becerileri ile internet kullanımına yönelik ileri beceri ve gelişimi kapsayan iki alt boyuta ayrılmıştır. İlki, dijital cihazların ve internetin kullanımını içeren faaliyetlerin sayısı ve karmaşıklığına dayalı olarak hesaplanan Komisyonun dijital beceri göstergesine ilişkin bir değerlendirmedir. İkinci alt boyut, dijital ekonomiyi geliştirmenin yanı sıra işgücü ve çalışma potansiyeli ile ilgilidir. Bu, BİT uzmanlığı becerilerini ortaya koyan işgücündeki kişilerin payını dikkate almaktadır. İnternet hizmetlerinin kullanımı, internet bağlantısı ve bundan yararlanmak için gerekli becerilere sahip vatandaşların katıldığı çeşitli çevrimiçi etkinlikleri değerlendirmektedir. IDESI'nın dijital teknolojinin entegrasyonu boyutu şirketlerin dijitalleşmesini ve e-ticaret faaliyetlerini ölçmektedir. Şirketlerin dijitalleşmesi iki alt göstergeden oluşmaktadır. Bunlar en son teknolojilerin mevcudiyeti ve firma düzeyinde teknoloji yayılımıdır. E-ticaret boyutu ise internetten satış yapan KOBİ'ler ve güvenli internet sunucularını oluşturmaktadır. IDESI'nın son göstergesi olan dijital kamu hizmetleri ise e-devlet işlemlerini kapsamaktadır (European Comission, 2020).

Çalışmanın bir diğer bağımsız değişkeni olan Küresel Rekabet Gücü Endeksi (The Global Competitiveness Index-GCI) Dünya Ekonomik Forumu tarafindan ölçülmekte ve ülkelerin küresel düzeyde rekabet edebilirliğini ölçmektedir. Endeks, 0-100 arasında değerler almaktadır. Bu çerçevede 0 değeri, ülkenin küresel rekabet gücünün en düşük olduğu seviyeyi, 100 değeri ise en yüksek olduğu değeri göstermektedir.

\subsection{Analiz Sonuçları}

Yatay kesit veri analizinde EKK tahmincileri ile ilgili değişen varyans problemi ortaya çıkabilmektedir. Tahmin edilen modelde değişen varyans problemi olduğu durumda elde edilen tahminciler sapmalı olabilecektir. Bundan dolayı, tahmin edilen modelde değişen varyans problemi, araştırmalarda yaygın olarak tercih edilen White (1980) tarafindan geliştirilen "White Değişen Varyans-Tutarl Standart Hatalar ve Kovaryans" testi (Wooldridge, 2001:55) ile araştırılmış ve tahmin edilen modelde değişen varyans probleminin olmadığı tespit edilmiştir. 2018 y1lı için IDESI ve IDESI göstergelerinin, SDGI üzerindeki etkisinin incelendiği ve 28 AB ülkesinin analize dâhil edildiği, Model 1 ve 2 için EKK yöntemi analiz sonuçları Tablo 3'de gösterilmektedir. 
Tablo 3. EKK Yöntemi Analiz Sonuçları

\begin{tabular}{|c|c|c|}
\hline \multirow{2}{*}{ Bağımsız Değişkenler } & \multicolumn{2}{|c|}{ Bağımlı Değişken: LSDGI } \\
\hline & Model 1 & Model 2 \\
\hline Sabit & $\begin{array}{c}1.173848 * \\
(0.0000)\end{array}$ & $\begin{array}{c}1.710474 * \\
(0.0000)\end{array}$ \\
\hline LIDESI & $\begin{array}{c}0.100933^{*} \\
(0.0001)\end{array}$ & \\
\hline LGCI & $\begin{array}{c}0.291832 * \\
(0.0003)\end{array}$ & \\
\hline $\mathbf{L C}$ & & $\begin{array}{c}0.032813 \\
(0.7986)\end{array}$ \\
\hline LHC & & $\begin{array}{c}0.025966 \\
(0.5307)\end{array}$ \\
\hline LCUI & & $\begin{array}{c}-0.027051 \\
(0.5396)\end{array}$ \\
\hline LIDT & & $\begin{array}{c}0.074741 * \\
(0.0016)\end{array}$ \\
\hline LDPS & & $\begin{array}{c}0.001415 \\
(0.9624)\end{array}$ \\
\hline$R^{2}$ & 0.703558 & 0.674414 \\
\hline F-İstatistik & $\begin{array}{l}29.66680^{*} \\
(0.000000)\end{array}$ & $\begin{array}{l}9.114115^{*} \\
(0.000083)\end{array}$ \\
\hline White Testi & $\begin{array}{c}8.116353 \\
(0.1499)\end{array}$ & $\begin{array}{c}24.25722 \\
(0.2313)\end{array}$ \\
\hline
\end{tabular}

Not: Parantez içindeki değerler katsayıların ihtimal değerlerini göstermektedir.

*, tahmin edilen katsayıların \%1 önem düzeyinde istatistiksel olarak anlamlı olduğunu göstermektedir.

Tablo 3'de görüldügü gibi, Model 1 analiz sonuçlarına göre, analize dâhil edilen IDESI ve GCI değişkenlerine ait katsayılar \%1 önem düzeyinde istatistiksel olarak anlamlıdır. IDESI ve GCI değişkenlerinin SDGI üzerindeki etkisi pozitiftir. Başka bir ifadeyle IDESI'daki \%1'lik artış, SDGI'y1 \%0.10 artırırken, GCI'daki \%1'lik artış SDGI'y1 \%0.29 artırmaktadır. IDESI göstergelerinin, SDGI üzerindeki etkisinin incelendiği Model 2'de sadece IDT değişkenine ait katsayı \%1 önem düzeyinde istatistiksel olarak anlamlıdır. IDT'deki \%1'lik artışın, SDGI'yı \%0.07 artırdığı sonucuna ulaşılmıştır. Analiz bulguları IDT dışında kalan diğer IDESI göstergelerinin SDGI üzerinde etkisinin olmadığını göstermiştir.

Tablo 3'de yer alan birinci modelde $R^{2}$ değeri 0.70, ikinci modelde bu değer 0.67'dir. Dolayısıyla her iki model için de bağımlı değişkendeki (SDGI) değişmenin \%0.70'i, bağımsız değişkenlerdeki değişmelerden kaynaklanmaktadır. Belirlilik katsayısı olarak adlandırılan ve modelin anlamlılık düzeyini gösteren $R^{2}$, yatay kesit veri analizinde genellikle küçük değerler almaktadır. Bu analizlerde Wallace ve Silver (1988) ile Studenmund (1992)'e göre genellikle $R^{2}, 0.3$ ve daha düşük değerde bulunmaktadır. Ayrıca yatay kesit verilerinde 0.5 büyüklüğünde bir $R^{2}$ değeri, iyi bir uygunluk değeri olarak görülmektedir (Ata, 2011:127-128; Ağır ve Kar, 2010:167, Altay Topcu ve Sümerli Sarıül, 2018:420).

Elde edilen bulgulara göre modellerden elde edilen $R^{2}$ değerleri, söz konusu yazarların ifade ettiği iyi bir uygunluk değerini aşmaktadır. Bu değerler modellerin açıklama gücünün yüksek olduğunu göstermektedir. $\mathrm{F}$ istatistik değerlerine göre, Tablo 3'de yer alan tüm modeller, \%1 önem düzeyinde bir bütün olarak anlamlıdır. 


\section{SONUÇ}

Dünyada fosil yakıtların yoğun olarak kullanımı, arazi kullanımındaki değişiklikler, ormansızlaştırma ve sanayi süreçleri gibi insan faaliyetleri atmosfere salınan sera gazı miktarının artmasına neden olmaktadır. Bunun sonucunda yerkürenin ortalama yüzey sıcaklıklarındaki artış ve ortaya çıkan iklim değişiklikleri küresel düzeyde tüm dünyayı tehdit eder hale gelmiştir. Bu çerçevede araştırmacıların ilgi odağı sürdürülebilir kalkınma üzerine yoğunlaşmıştır. Bu çerçevede BİT’lerdeki gelişmeler ve dijital ekonomiye geçiş süreci de çevreye önem veren kalkınma olarak da bilenen sürdürülebilir kalkınma üzerinde önemli bir unsur haline gelmiştir.

Dijitalleşmeyle birlikte artan enerji ve kaynak tüketiminin kontrol altına alınmasıyla bu faktörlerin çevre üzerinde yaratmış olduğu baskılar azaltılabilir. Diğer taraftan, dijitalleşme günümüzde işletmeler açısından değerlendirildiğinde, rekabet avantajı sağlayabilen en önemli faktördür. İşletmelerin devamlılıklarını sağlayabilmeleri, bir başka deyişle, sürdürülebilir olmaları dijitalleşme ile mümkün olacaktır. Bu nedenle işletmeler dijitalleşmeye önem vermek ve dijital dünyadaki değişmeleri takip ederek uygulamak zorunda kalmışlardır. Dijitalleşmenin işletmeler açısından son derece önemli bir kavram haline gelmesinin nedeni, yapılan işlemlerin hızlı, pratik ve verimli bir şekilde yürütülmesinden kaynaklanmaktadır. Ayrıca dijitalleşme işletmelerin yeni fikirler geliştirmelerini, daha geniş bir tüketici kitlesine ulaşmalarını, faaliyetlerini organize edip yönetmelerini sağlamaktadır. İşletmeler bu sayede müşterilerine daha iyi ürün ve hizmet sunarak, onların memnuniyetini ve sadakatini artırabilmektedir.

Özellikle son dönemlerde yaşanan Covid-19 salgını nedeniyle internet tabanlı teknolojilerin yaygın olarak kullanılması, dijitalleşmenin etkilerinin çeşitli sektörlerde ortaya çıkmasına neden olmuştur. Günümüzde sadece sektörel bazda faaliyet gösteren işletmeler değil de, aynı zamanda toplumdaki bireyler de birçok alanda dijital teknolojilerden faydalanmaktadır. Bu nedenle özellikle bireylerin mobil uygulamalara olan talep ile internette geçirdiği sürelerin artması, günlük hayattaki tüm sosyalleşme süreçlerinin dijital ortamda yapılması ile birlikte e-ticaret hacminde artış yaşanmıştır.

Çalışmada Avrupa Komisyonu tarafından 2020 yılında yayınlanan IDESI indeksinden yararlanarak dijital ekonomi ve göstergelerinin $\mathrm{AB}$ ülkelerinde 2018 y1lı için sürdürülebilir kalkınma üzerindeki etkinliği araştırılmıştır. Araştırma sonucunda dijital ekonominin sürdürülebilir kalkınma üzerinde pozitif etkisinin olduğu, dijital ekonomi göstergelerinden sadece dijital ekonomiye entegrasyonun sürdürülebilir kalkınmay1 artırdığı sonucuna ulaşılmıştır. İşletmelerin dijitalleşmesi ve çevrimiçi satış kanallarının geliştirilmesi anlamına gelen dijital ekonomiye entegrasyon süreci ve bu sürecin geliştirilmesi; doğrudan ekonomik büyüme, gelişme ve sürdürülebilir kalkınma kavramlarını ilgilendiren bir dijital ekonomi göstergesidir. Bu göstergenin sürdürülebilir kalkınma üzerindeki etkinliğinin büyük ölçekte artırılabilmesi temelde BİT'lerin geliştirilmesi ve işletmeler tarafından bu sürecin doğru yönetimi ile mümkün olacaktır. Analiz bulguları dijital ekonominin AB pazarında sürdürülebilir kalkınmanın önemli bir parçası olduğunu ve dijital teknolojideki gelişmelerin bu süreci daha da iyiye götürebileceğini göstermiştir.

$\mathrm{Bu}$ konu ile ilgili araştırmacıların yapacağı çalışmalarda, $\mathrm{AB}$ IDESI raporlarından yararlanılarak $\mathrm{AB}$ ve $\mathrm{AB}$ dışındaki ülkelerin pazarlarında dijital ekonominin, sürdürülebilir kalkınma üzerindeki etkisi analiz edilerek karşılaştıılabilir. Ayrıca AB tarafından gelecek yıllarda yayınlanması muhtemel olan endeks raporlarının Covid-19 salgın sürecini kapsayabilecek olması nedeniyle de özellikle de bu sürecin dijital dönüşüm etkisi daha fazla olacağı için, bu verilerin analize dâhil edilmesi daha anlamlı sonuçların ortaya çıkmasına neden olabilir. 2020 yılında $A B$ tarafından yayınlanan endeks raporunda analiz edilebilecek veri dönemi 2015-2018 dönemini kapsamaktadır. Daha önce yayınlanmış olan raporlarda da endeks ölçeklendirilmesinde 0-1 aralığında değerler alınmıştır. Bu ölçeklendirme 2020 yılı raporunda 0-100 değerleri şeklinde güncellenmiştir. Gelecek yıllarda da aynı ölçeklendirme kullanılabilirse araştırmacılar panel veri analiz yöntemi ile de bu ilişkiyi analiz edebilme imkânı sağlayabilir. 


\section{KAYNAKÇA}

AĞIR, Hüseyin ve KAR, Muhsin (2010), “Türkiye'de Elektrik Tüketimi ve Ekonomik Gelişmişlik Düzeyi İlişkisi: Yatay Kesit Analizi”, Sosyoekonomi, S.6(12-Enerji Özel Sayıs1), ss.149-176.

AKKAYA, Hüseyin ve GERÇEK, Adnan (2019), "OECD ve Seçilmiş Bazı Ülkelerde Dijital Ekonominin Vergilendirilmesi: Türkiye İçin Çıkarımlar”, International Journal of Public Finance, S.4(2), ss.166188.

ALTAY TOPCU, Betül ve SÜMERLİ SARIGÜL, Sevgi (2018), "Lojistik Performansin İhracat Üzerindeki Etkisi”, Recent Discussions in Social Sciences (Ed. Mustafa Talas, Hasan Çiftçi, Elvan Yalçınkaya), İKSAD Yayınevi, Ankara, ss.408-426.

ALTAY TOPCU, Betül ve SÜMERLİ SARIGÜL, Sevgi (2020), "Dünyada ve Türkiye'de Blok Zinciri Teknolojisi: Finans Sektörü, Dış Ticaret ve Vergisel Düzenlemeler Üzerine Genel Bir Değerlendirme”, Avrupa Bilim ve Teknoloji Dergisi, S.(Özel Say1), ss.27-39.

ANUŞLU, Merve Doğruel ve FIRAT, Seniye Ümit (2020), "Ülkelerin Endüstri 4.0 Seviyesinin Sürdürülebilir Kalkınma Düzeylerine Etkisinin Analizi”, Endüstri Mühendisliği, S.31(0), ss.44-58.

ATA, Ahmet Yılmaz (2011), “Ücretler, İşsizlik ve Suç Arasındaki İlişsi: Yatay Kesit Analizi”, Çalışma ve Toplum, S.4, ss.113-134.

BARIŞIK, Salih ve YİRMIBEŞÇİK, Oya (2006), “Türkiye'de Yeni Ekonominin Oluşum Sürecini Hızlandırmaya Yönelik Uyum Çabaları”, ZKÜ Sosyal Bilimler Dergisi, S.2(4), ss.39-62.

BERTELSMANN STIFTUNG AND SUSTAINABLE DEVELOPMENT SOLUTIONS NETWORK (2018), SDG Index and Dashboards Report 2018, Global Responsibilities Implementing the Goals, New York.

BİLGílí, Muhammed Yunus (2017), "Ekonomik, Ekolojik ve Sosyal Boyutlartyla Sürdürülebilir Kalkınma”, Journal of International Social Research, S.10(49), ss.559-569.

BUKHT, Rumana ve HEEKS, Richard (2017), "Defining, Conceptualising and Measuring the Digital Economy", Manchester Centre for Development Informatics Working Paper, S.68, ss.1-24.

CARLSSON, Bo (2004), "The Digital Economy: What is New and What is Not?", Structural Change and Economic Dynamics, S.15, ss.245-264.

DAVID, Oladipo Olalekan (2019), "Nexus Between Telecommunication Infrastructures, Economic Growth and Development in Africa: Panel Vector Autoregression (PVAR) Analysis", Telecommunications Policy, S.43, ss.1-17.

DENIZ, Müjgan (2018), "Dijital Ekonominin Ülke Ekonomileri Içerisinde Artan Etkisi: AB Üye Ülkeleri ve Gelişmiş Ekonomiler Üzerine Bir Inceleme", 4th Eurasian Conference on Language and Social Sciences, July 24-27, Riga - Latvia, ss.89-105.

DINANA, Hesham O. (2019), "The Impact of Information \& Communication Technologies (ICT) on Sustainable Development Goals (SDGs) Progression in the Era of Digital Economy”, Sustainable Development Conference, Bangkok - Tahiland, ss.1-13.

DİKKAYA, Mehmet ve AYTEKİN, İbrahim (2019), “Bilgi İletişim Teknolojileri ve Dijital Ekonomi: Avrupa Birliği ve Türkiye Arasında Bir Karşılaştırma", Üçüncü Sektör Sosyal Ekonomi Dergisi, S.54(3), ss.1279-1299.

DRUCKER, Peter F. (1993), Post-Capitalist Society, HarperBusiness, New York (USA).

EUROPEAN COMISSION (2020), International Digital Economy and Society Index, Final Report.

GÖZÜKÜÇÜK, Mustafa Fikret (2020), "Dijital Dönüşüm ve Ekonomik Büyüme”, Yayınlanmamış Yüksek Lisans Tezi, İstanbul Ticaret Üniversitesi Sosyal Bilimler Enstitüsü, İstanbul.

HEGYES, Éva Görgényi, CSAPO, Ildikó ve FARKAS, Mária Fekete (2017), "Some Aspects of Digitalization and Sustainability in the European Union", Journal of Management, S.31(2), ss.37-46.

HILTY, Lorenz M. ve HERCHEUI, Magda David (2010), "ICT and Sustainable Development”, IFIP AICT, S.328, ss.227-235. 
JOVANOVIĆ, Milica, DLAČIĆ, Jasmina ve OKANOVIĆ, Milan (2018), "Digitalization and Society's Sustainable Development-Measures and Implications", Zbornik Radova Ekonomskog Fakulteta u Rijeci/Proceedings of Rijeka Faculty of Economics, S.36(2), ss.905-928.

KAYPAK, Şafak (2011), "Küreselleşme Sürecinde Sürdürülebilir Bir Kalkınma İçin Sürdürülebilir Bir Çevre”, KMÜ Sosyal ve Ekonomik Araştırmalar Dergisi, S.13(20), ss.19-33.

KONU, Aylin (2020), "Sürdürülebilir Kalkınma ve Dijital Ekonomi İlişkisi: AB Ülkeleri İçin Bir Araştırma", Akademik İncelemeler Dergisi, S.15(2), ss.655-678.

LI, Kai, KIM, Dan J., LANG, Karl R., KAUFFMAN, Robert J. ve NALDI, Maurizio (2020), "How Should We Understand the Digital Economy in Asia? Critical Assessment", Electronic Commerce Research and Applications, S.44, ss.1-16.

MASTAR ÖZCAN, Pelin (2016), "Dijital Ekonominin Vergilendirilmesinde Karşılaşılan Sorunlar: BEPS 1 No'lu Eylem Planı Kapsamında Bir Değerlendirme”, Electronic Journal of Vocational Colleges, ss.7382.

MORELLI, John (2011), "Environmental Sustainability: A Definition for Environmental Professionals", Journal of Environmental Sustainability, S.1(1), ss.1-9.

OECD (2019), Tax Challenges Arising from Digitalisation-Interim Report 2019, Inclusive Framework on BEPS, OECD/G20 Base Erosion and Profit Shifting Project, OECD Publishing, Paris.

PRADHAN, Rudra P., ARVIN, Mak B., NAIR, Mahendhiran, BENNETT, Sara E. ve BAHMANI, Sahar (2019), "Short-Term And Long-Term Dynamics of Venture Capital and Economic Growth in A Digital Economy: A Study of European Countries", Technology in Society, S.57, ss.125-134.

REZNY, Lukas, WHITE, James Buchanan ve MARESOVA, Petra (2019), “The Knowledge Economy: Key to Sustainable Development?”, Structural Change and Economic Dynamics, S.51, ss.291-300.

SERINIKKLİ, Nilüfer (2021), "Covid-19 Salgın Sürecinde Örgütsel Değişim: Uzaktan/Evden Çalışma Modeli”, Firat Üniversitesi Sosyal Bilimler Dergisi, S.31(1), ss.277-288.

TAPSCOTT, Don (1995), The Digital Economy: Promise and Peril in the Age of Networked Intelligence, McGraw-Hill Publisher, New York.

TAŞEL, Fulya (2020), "Dijitalleşmenin Ticarete ve Ekonomiye Etkisi”, Beykoz Akademi Dergisi, S.8(2), ss.127-137.

TIRAŞ, H. Hayrettin (2012), "Sürdürülebilir Kalkınma ve Çevre: Teorik Bir Inceleme”, Kahramanmaraş Sütçü İmam Üniversitesi İktisadi ve İdari Bilimler Fakültesi Dergisi, S.2(2), ss.57-73.

TOCAN, Madalina ve DUDUMAN, Stefan-Gabriel (2010), "Sustainable Development-Strategic Goal of The Knowledge Based Economy”, Munich Personal RePEc Archive, Paper No. 41588, ss.1-15.

UNITED NATIONS (tarihsiz), The Sustainable Development Goals, https://sdgs.un.org/goals (Erişim Tarihi: 20.05.2021).

VIVIEN, F. Dominique (2008), "Sustainable Development: An Overview of Economic Proposals", SAPIENS, S.1(2), ss.1-8.

WHITE, Halbert (1980), “A Heteroskedasticity-Consistent Covariance Matrix Estimator and A Direct Test for Heteroskedasticity”, Econometrica, S.48(4), ss.821-827.

WOOLDRIDGE, Jeffrey M. (2001), Econometric Analysis of Cross Section and Panal Data, The MIT Press, Cambridge - London (England).

WORLD ECONOMIC FORUM (2019), The Global Competitiveness Report 2019, World Economic Forum Publisher, Cologny - Geneva (Switzerland).

YEŞiLORMAN, Mehtap ve KOÇ, Firdevs (2014), “Bilgi Toplumunun Teknolojik Temelleri Üzerine Eleştirel Bir Bakış", Fırat Üniversitesi Sosyal Bilimler Dergisi, S.24(1), ss.117-133. 